\title{
An Experiment to Measure the Usefulness of Patterns in the Interaction Design Process
}

\author{
N.L.O. Cowley and J.L. Wesson \\ P.O. Box 77000, Nelson Mandela Metropolitan University, \\ Port Elizabeth, South Africa, 6031 \\ \{Janet.Wesson, Lester.Cowley\} @nmmu.ac.za
}

\begin{abstract}
Interaction design patterns have yet to prove themselves in interaction design in the way that design guidelines have. This paper describes an empirical study comparing the use of patterns and guidelines. The study involved a heuristic evaluation of a web site, the redesign of the web site, and the design of a new web site. Preliminary results suggesting that developers find patterns useful in the interaction design process are presented. Further analysis using heuristics to compare the quality of the designs produced using patterns and guidelines will provide an objective assessment of the usefulness of patterns.
\end{abstract}

\section{Introduction}

Interaction design (ID) is concerned with designing interactive products to support people in their everyday lives. ID consists of four activities: identifying user needs and establishing requirements, developing alternative designs, building interactive versions, and evaluating the usability of these versions. Successful ID requires a usercentered focus, iterative design and evaluation. The design activity involves the design of the conceptual model and the physical design.

Design guidelines are a commonly used and generally accepted aid for physical design and can be used as heuristics for expert evaluation of existing systems. Guidelines summarize good practice, are easy to understand and apply, but are sometimes contradictory. Interaction design patterns have been proposed as alternatives to guidelines. Various researchers have described the advantages of patterns, including Griffiths and Pemberton [1], Tidwell [2], Dearden et al. [3], and Van Welie and van der Veer [4].

Empirical evidence about pattern use is limited. As an evaluation aid, there is evidence that guidelines may be easier to use and more effective than patterns [5]. There is little evidence that interfaces designed using patterns are better than the equivalent interfaces designed using guidelines $[2,6]$. Existing pattern collections are works in progress and the patterns may be deficient in form or content. The pattern languages (PLs) in the collections may be lacking, fragmentary or inconsistent.

An investigation into the use of interaction design patterns was conducted in 2004. The aim of the investigation was to evaluate the use of patterns in interaction design, the quality of the patterns used and the interfaces produced. An experimental group 
used selected patterns to evaluate and redesign an existing website and to design a new website. A control group used similar guidelines to carry out the same tasks.

\section{Research Design}

Several research questions were formulated (Table 1). The primary research question was to determine to what extent patterns are a useful interaction design aid.

Table 1. Interaction Design Patterns Research Questions

\begin{tabular}{|l|l|}
\hline Question & To what extent are patterns: \\
\hline $1-3$ & An efficient, effective and satisfying evaluation aid? \\
\hline $4-6$ & An efficient, effective and satisfying redesign aid? \\
\hline $7-9$ & An efficient, effective and satisfying design aid? \\
\hline $10-11$ & Useful in terms of their format and content? \\
\hline 12 & Useful when linked together into a pattern language? \\
\hline 13 & Easy to become familiar with when first encountered? \\
\hline $14-15$ & A personal and shared design language? \\
\hline
\end{tabular}

Thirty-three Computer Science masters and honours students registered for a postgraduate E-commerce course were recruited for the study. Stratified sampling was employed to split the group into equivalent experimental and control groups. A pretest questionnaire was used to record the participants' biographical data. The Porcupine Ceramics website (http://www.porcupine.co.za/) was chosen as a suitable E-commerce web site for evaluation and redesign.

The pattern collections selected for use by the experimental group were van Welie's Amsterdam Pattern Collection [7] and van Duyne et al.'s Design of Sites Pattern Browser [8]. The design guidelines selected for use by the control group were Barnard's E-commerce guidelines [9], which are based on those proposed by Nielsen et al. [10]. Permission to use these resources was obtained from their owners.

The experimental group carried out three tasks using patterns while the control group carried out the same tasks using guidelines. The first task was to perform a heuristic evaluation of the Porcupine Ceramics website. The second task was to redesign the Porcupine Ceramics website and to evaluate the content of the design aids used. The third task was to design a new E-commerce website from specifications, and to evaluate the form of the design aids. The groups documented their designs using sitemaps and detailed wireframes (as high-fidelity prototypes).

Each group was provided with a list of suggested patterns or guidelines to use. Suggested patterns included Shopping Experience, Shopping Cart, Product Page, Login and Register (from the Amsterdam Pattern Collection). Suggested guidelines included Customer Support, Shopping Cart \& Placing Order and Product Pages (from Barnard's E-commerce guidelines). The participants used project diaries to record their mental processes and experiences while they carried out the tasks.

A post-test questionnaire was used to record quantitative and qualitative data about the participants' attitudes towards the design aids used. The items were grouped into five categories: Evaluation, Redesign, New Design, Format and Content, and General 
Experience. Several statements were presented in each category, relating to the research questions in Table 1. The participants rated the statements in the five categories, using a five-point Likert scale, with 1 indicating Strongly Disagree and 5 indicating Strongly Agree. Open-ended items were used to collect qualitative data.

\section{Preliminary Research Results}

Preliminary results obtained for the post-test questionnaire items are summarised in Table 2. Interval-data descriptive statistics were calculated for each of the statements, including means and standard deviations. The $\mathrm{N}$ values indicate the number of data items used in the calculations. Initial estimates of whether the pattern hypotheses can be accepted (A) or not accepted (N) appear in the Result column.

Table 2. Results of Analysis of Post-Test Questionnaire Quantitative Data

\begin{tabular}{|c|c|c|c|c|c|c|c|c|c|}
\hline \multirow[b]{2}{*}{ 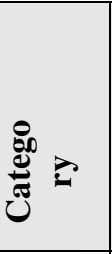 } & \multirow[b]{2}{*}{ Property } & \multirow{2}{*}{ 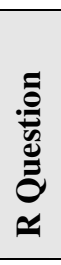 } & \multicolumn{3}{|c|}{$\begin{array}{l}\text { Guideline } \\
\text { Users }\end{array}$} & \multicolumn{4}{|c|}{ Pattern Users } \\
\hline & & & $\mathbf{N}$ & $\sum^{\tilde{E}}$ & 离 & $\mathbf{N}$ & $\sum^{\Xi}$ & 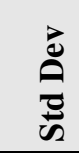 & 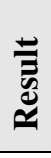 \\
\hline \multirow{3}{*}{ 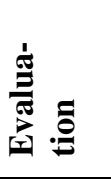 } & Efficiency & 1 & 20 & 3.8 & 0.6 & 30 & 3.6 & 1.0 & $\mathrm{~A}$ \\
\hline & Effectiveness & 2 & 20 & 4.0 & 0.8 & 30 & 3.5 & 0.9 & $\mathrm{~A}$ \\
\hline & Satisfaction & 3 & 19 & 3.5 & 0.8 & 30 & 3.1 & 1.3 & $\mathrm{~N}$ \\
\hline \multirow{3}{*}{ 莺 } & Efficiency & 4 & 20 & 3.6 & 0.8 & 31 & 3.6 & 0.9 & $\mathrm{~A}$ \\
\hline & Effectiveness & 5 & 20 & 3.7 & 0.7 & 31 & 3.6 & 0.9 & $\mathrm{~A}$ \\
\hline & Satisfaction & 6 & 20 & 3.3 & 0.8 & 31 & 3.3 & 1.2 & $\mathrm{~N}$ \\
\hline \multirow{3}{*}{ 总 } & Efficiency & 7 & 40 & 3.3 & 0.8 & 60 & 3.5 & 1.1 & $\mathrm{~A}$ \\
\hline & Effectiveness & 8 & 20 & 3.7 & 0.8 & 29 & 3.8 & 0.8 & A \\
\hline & Satisfaction & 9 & 20 & 3.3 & 0.9 & 30 & 3.6 & 1.1 & $\mathrm{~A}$ \\
\hline \multirow{3}{*}{ 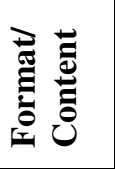 } & Form & 10 & 21 & 3.4 & 1.2 & 34 & 3.4 & 1.1 & A \\
\hline & Content & 11 & 20 & 3.3 & 1.3 & 34 & 3.5 & 1.0 & $\mathrm{~A}$ \\
\hline & Organisation & 12 & 10 & 4.3 & 0.7 & 33 & 3.5 & 1.0 & $\mathrm{~A}$ \\
\hline \multirow{3}{*}{ 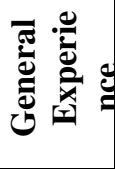 } & Learnability & 13 & 33 & 3.4 & 1.0 & 48 & 3.4 & 1.0 & $\mathrm{~N}$ \\
\hline & Personal Lang. & 14 & 11 & 3.5 & 0.7 & 16 & 3.7 & 0.9 & $\mathrm{~A}$ \\
\hline & Shared Lang. & 15 & 8 & 3.1 & 1.0 & 15 & 3.1 & 1.1 & $\mathrm{~N}$ \\
\hline
\end{tabular}


Based on the above results, we can conclude that designers consider patterns to be an efficient and effective aid for evaluation, redesign and new design; that the form and content of the pattern collections is generally seen as useful; and that designers consider patterns to be a personal design language. It is noteworthy that both groups were equally strongly positive about using the different design aids in future projects.

\section{Conclusions and Future Work}

This paper has presented some empirical evidence that designers consider patterns to be useful for interaction design. Analysis of the post-test qualitative data and the project diaries will provide additional information about the attitudes and design rationales of the two groups, in order to better understand the interaction design process. Future work using heuristics to compare the quality of the designs produced using patterns and guidelines will provide an objective assessment of the usefulness of patterns in the interaction design process.

\section{References}

1. Griffiths, R.N. and Pemberton, L: Don't Write Guidelines Write Patterns! (2000) [cited 30 March 2005]; Available from: http://www.it.bton.ac.uk/staff/lp22/guidelinesdraft.html

2. Tidwell, J.: Common Ground: A Pattern Language for Human-Computer Interface Design. (1998) [cited 30 March 2005]; Available from: http://www.mit.edu/ jtidwell/ common_ground.html

3. Dearden, A., Finlay, J., Allgar, E. and McManus, B.: Using Pattern Languages in Participatory Design. In Binder, T., Gregory, J. \& Wagner, I (eds.): PDC 2002, Proceedings of the Participatory Design Conference. CPSR, Palo Alto, CA., (2002). $104-113$

4. Van Welie, M. and van de Veer, G.C.: Pattern Languages in Interaction Design: Structure and Organisation. In IFIP INTERACT '03. 2003. Zurich, Switzerland: IOS Press.

5. Wesson, J.L. and Cowley, N.L.O.: Designing with Patterns: Possibilities and Pitfalls. in IFIP INTERACT'03 Workshop on Software \& Usability Cross-Pollination: The Role of Usability Patterns. (2003). Zurich, Switzerland.

6. Kok, D. and Wesson, J.L.: Designing Transaction Processing Systems: A Patterns Approach. In South African Institute of Computer Scientists \& Information Technologists Conference (SAICSIT) 2002. (2002). Port Elizabeth, South Africa.

7. Van Welie, M. and Trætteberg, H.: The Amsterdam Collection of Patterns in User Interface Design. (2001) [cited 30 March 2005]; Available from: http://www.cs.vu.nl/ $\sim$ martijn/patterns/PLoP2k-Welie.pdf

8. Van Duyne, D.K., Landay, J.A. and Hong, J.I.: The Design of Sites: Patterns, Principles, and Processes for Crafting a Customer-Centered Web Experience. Addison-Wesley, Pearson Education, Boston (2003)

9. Barnard, L.: An Investigation into Usability Issues for E-Commerce in South Africa. PhD thesis, University of Port Elizabeth (2004)

10. Nielsen, J., Molich, R., Snyder, C. and Farrell, S.: E-Commerce User Experience: Highlevel Strategy. Nielsen Norman Group (2001). 